\title{
INSTITUCIONES FORMALES DE LA GOBERNANZA METROPOLITANA EN COLOMBIA: UN ANÁLISIS DE ELECCIÓN RACIONAL ${ }^{*}$
}

\author{
Luis Miguel Roldán Alzate**
}

\section{Resumen}

En este artículo se indaga por las condiciones necesarias para la cooperación de municipios colindantes en la integración de áreas metropolitanas en Colombia a partir de una revisión, bajo el marco analítico del institucionalismo de elección racional, de las principales teorías sobre el gobierno metropolitano y la normativa vigente relacionada con la jurisdicción metropolitana en el país. Se concluye que la conformación de un área metropoli- tana en Colombia obedece a la existencia de beneficios extraordinarios para los municipios participantes, y que el fortalecimiento de la gobernanza metropolitana depende, bien del mantenimiento de dichos beneficios o bien de un fortalecimiento de los mecanismos de veeduría que modifiquen los incentivos a los hacedores de políticas.

Palabras clave: gobernanza metropolitana, elección racional, institucionalismo, cooperación.

* La investigación que da lugar a este artículo se realizó durante 2016, y se redactó durante el segundo semestre de este año. El artículo es realizado por el autor como parte de su trabajo dentro del programa Medellín Cómo Vamos, y como un producto asociado a la investigación realizada en el marco de la maestría en Ciencia Política de la Universidad de Antioquia. Fue presentado de forma preliminar en el coloquio de investigadores del grupo RERDSA que tuvo lugar en diciembre de 2016.

** Economista de la Universidad EAfit y estudiante de maestría en Ciencia Política del Instituto de Estudios Políticos de la Universidad de Antioquia. Profesional en el Programa Medellín Cómo Vamos y miembro del grupo de investigación en Recursos Estratégicos, Región y Dinámicas Socioambientales (RERDSA) del Instituto de Estudios Regionales de la Universidad de Antioquia, Medellín (Colombia). [lmiguel.roldan@udea.edu.co].

Recibido: 23/01/2017/ Modificado: 3/05/2017/ Aceptado: 01/06/2017.

Para citar este artículo

Roldán Alzate, L. M. (2017). Instituciones formales de la gobernanza metropolitana en Colombia: un análisis de elección racional. OPERA, 21, pp. 113-132.

DOI: https://doi.org/10.18601/16578651.n21.07 
FORMAL INSTITUTIONS OF METROPOLITAN GOVERNANCE IN COLOMBIA: A RATIONAL CHOICE ANALYSIS

\section{Abstract}

This article analyses the necessary conditions for cooperation of neighboring municipalities in the integration of metropolitan areas in Colombia. This is based on a review, under the analytical framework of rational choice, of the main theories concerning metropolitan government, and of the current regulations related to the metropolitan jurisdiction in the country. It has been concluded that the creation of a metropolitan area in Colombia depends on the existence of extraordinary benefits for the participating municipalities, and that the strengthening of metropolitan governance depends either on the maintenance of such benefits or on the strengthening of social accountability mechanisms that could modify policy makers' incentives.

Key words: Metropolitan governance, rational choice theory, institutionalism, cooperation.

\section{INTRODUCCIÓN}

En Colombia, las áreas metropolitanas son entidades administrativas establecidas como mecanismo de cooperación entre municipios conurbados ${ }^{1}$. El marco normativo que establece las condiciones para su conformación y mantenimiento, así como sus competencias, ha venido ampliándose desde la promulgación de la reforma constitucional de 1968 que creó la figura, y del Decreto-Ley 3104 de 1979 que dio lugar a la constitución de las primeras áreas metropolitanas en la década de los ochenta ${ }^{2}$, con la inclusión, dentro de la Constitución Política de 1991, de la figura de Área Metropolitana como entidad administrativa, la promulgación de la Ley 128 de 1994 en cuanto a su estatuto general, la Ley 99 de 1993 en cuanto a lo ambiental, la Ley 169 de 2002, y el Decreto 170 de 2001 en cuanto al transporte, y las leyes 388 de 1997 y 1454 en cuanto a su función de planificación territorial, entre otras piezas normativas. En 2013, con la promulgación de la Ley 1625 que establece un nuevo régimen de áreas metropolitanas, se crean disposiciones que amplían las competencias de estas entidades y los requisitos para su conformación.

Algunas de las competencias y funciones asignadas desde esta última ley a las áreas metropolitanas son de coordinación, específicamente en la planificación del desarrollo territorial, y no limitan de forma significativa las capacidades municipales. Otras son funciones que reducen o modifican las de los municipios, especialmente las relacionadas con el ejercicio de la autoridad ambiental y de transporte.

1 Las áreas metropolitanas son una forma regulada específica de esquema asociativo territorial, tal y como se especifica en la Ley 1454 de 2011 (art. 10).

2 A 2009 había en Colombia cinco áreas metropolitanas constituidas: "Área metropolitana de Barranquilla (Ordenanza 28 de 1981); Área metropolitana de Bucaramanga (Ordenanzas 20 de 1981 y 46 de 1984); Área metropolitana de Cúcuta (Ordenanza 49 de 1990 y Decreto 0508 de 1991); Área metropolitana del Valle de Aburrá (Ordenanza 34 de 1981); y Área metropolitana de Centro-Occidente (Ordenanzas 1 de 1981 y 14 de 1991)” (Carrión, 2009, p. 222). 
Este artículo realiza un análisis de la normativa relacionada con las áreas metropolitanas, limitándose a las instituciones formales. Basándose en elementos del análisis de elección racional, revisa la normativa vigente sobre la jurisdicción metropolitana en Colombia (especialmente la Ley 1625 de 2013).

El artículo está dividido en cuatro partes, además de la introducción. La primera de ellas explica y justifica el marco analítico que se utilizará, y presenta una revisión de las principales corrientes teóricas dentro de los estudios metropolitanos a partir de diversos autores, explicadas a partir del marco analítico propuesto. La segunda expone la normativa colombiana concerniente a la gobernanza metropolitana; comienza con una perspectiva histórica y luego, más en detalle, expone la regulación actual. La tercera parte discute dicha normativa a la luz de la metodología planteada. La cuarta parte presenta las conclusiones del trabajo.

\section{METODOLOGÍA Y REVISIÓN TEÓRICA}

La metodología de análisis propuesta parte de dos supuestos que apelan a corrientes académicas distintas pero convergentes. En primer lugar se parte, siguiendo a Downs (1992) ${ }^{3}$, de una situación en la cual los políticos, tanto en ejercicio como en campańa, maximizan el número total de votos alcanzados con la pretensión de alcanzar el poder si están por fuera, o mantenerse si están gobernando. Dicha búsqueda es racional, es decir, que propende siempre por la mayor utilidad con el menor uso de recursos escasos. En segundo lugar, se presta especial atención, siguiendo a Williamson (2000) y Ostrom (2015), a las condiciones institucionales de la gobernanza, entendidas las instituciones como las reglas de juego de una situación particular, y la gobernanza como una estructura-conformada por instituciones que, generalmente, se representan como contratosque permite gestionar adecuadamente una organización en el mediano plazo.

Tanto Ostrom (2015) como Williamson (2000) proponen cuatro niveles de análisis, establecidos a partir de la velocidad del cambio institucional. El primer nivel, denominado "situaciones operativas" desde la perspectiva de Ostrom, y "distribución de recursos y empleo" para Williamson, incluye las "acciones llevadas a cabo por los individuos que influyen directamente en las variables de estado del entorno" (Ostrom, 2015, p. 103). Las instituciones que regulan este tipo de situaciones específicamente cambian de manera continua. Ejemplos de estas situaciones son las transacciones de mercado. El segundo nivel de análisis, denominado "Situaciones de elección colectiva" por Ostrom (2015) y "Gobernanza” por Williamson (2000), es el ámbito en el cual las relaciones son mediadas esencialmente por contratos y, en consecuencia, las instituciones que regulan dichas relaciones cambian más lentamente. El tercer nivel es el de las instituciones formales, denominado por Ostrom (2015) como "situaciones constitucionales" y por Williamson (2000) como "entorno institucional". Este

\footnotetext{
3 La cita mencionada hace referencia a la traducción al español del texto original "An economic theory of political action in a democracy", publicado en 1957 en el Journal of Political Economy.
} 
nivel estudia las instituciones constitucionales, legales y jurídicas, y las relaciones o transacciones que están más directamente reguladas por estas instituciones.

La explicación del marco analítico básico de las instituciones para Ostrom (2015) y Williamson (2000) es importante en la medida en que el objeto del presente artículo son las relaciones que tienen lugar en el marco del entorno institucional, que facilitan una u otra estructura de gobernanza ${ }^{4}$ para un ambiente determinado. Sin embargo, se presta especial atención a las consecuencias del entorno institucional sobre el nivel inferior -el de la gobernanza-, donde los distintos actores toman decisiones de cooperación o competencia.

\section{Supuestos del modelo de elección racional}

Dentro de los estudios que utilizan el análisis de elección racional como enfoque metodológico, la definición de los supuestos sobre la conducta de los distintos actores es muy importante. Anthony Downs (1992) propuso un modelo básico de competencia electoral con información completa -es decir, donde todos los actores saben cuál será la conducta del otro, y además saben que los demás saben que ellos tienen ese conocimiento- aplicable para el gobierno local, cuyos supuestos son útiles para el análisis propuesto en este trabajo. A continuación se presentan algunos de estos supuestos 5 :

a) Gobernar le representa a un partido político un nivel de utilidad tal que amerita que sus miembros busquen estar en el poder por el mayor tiempo posible.

b) El partido político que gobierna tiene el control total de sus funciones hasta que termina su periodo.

c) "Las acciones de gobierno son una función de la forma en que se espera que voten los ciudadanos y de las estrategias de sus opositores" (Downs, 1992, p. 97).

d) "Los ciudadanos votan de acuerdo con: a) las variaciones que cause la actividad gubernamental en su utilidad y renta, y b) las alternativas ofrecidas por la oposición" (Downs, 1992, p. 97).

e) "La utilidad o renta que los votantes reciben de la actividad gubernamental depende de las acciones tomadas por el gobierno durante su mandato" (Downs, 1992, p. 97).

A pesar de que estos supuestos pueden ajustarse al gobierno local, no son suficientes para explicar fenómenos metropolitanos, por no considerar la influencia que puedan tener los

4 El nuevo institucionalismo concibe las estructuras de gobernanza como las formas que puede tomar una organización, desde una estructura rigurosamente vertical, con cadenas de mando sólidas, hasta una estructura de libre mercado (Ebers y Oerlemans, 2013). Si bien este enfoque ha sido usualmente utilizado en los estudios de organización industrial, es aplicable a la asociatividad territorial en entornos donde las entidades tienen un nivel relativamente alto de autonomía.

5 En total, el modelo de Downs (1992) con información incompleta incluye diez supuestos, de los cuales cinco son axiomas y cinco son proposiciones. Para efectos explicativos y por limitaciones de espacio, se presentan únicamente cinco de los supuestos. Una crítica de los supuestos de Downs (1992) puede encontrarse en Barry (1970). 
municipios vecinos sobre el estado de uno de los municipios. Además de los mencionados, es necesario agregar algunos supuestos al modelo básico ${ }^{6}$. Estos supuestos son, en general, construcciones propias del autor, derivadas de los supuestos anteriores, bien sea como complementos o como precisiones. Los supuestos 5 y 6 no se derivan del conjunto inicial. El supuesto 5 está basado en la literatura sobre gobernanza metropolitana, $y$ es utilizado como supuesto fundamental en modelos de elección racional como los presentados por Steinacker (2004). Por su parte, el supuesto 6 se basa en la idea de que las externalidades no son correctamente internalizadas por los ciudadanos, por lo que no perciben que su corrección sea prioritaria en el corto plazo.

1. Derivado del quinto supuesto listado previamente, las decisiones de voto de los ciudadanos dependen de las acciones de gobierno, pero los votantes no diferencian entre acciones de gobierno del nivel local, metropolitano, departamental o nacional.

2. La magnitud de las acciones de gobierno de todos los municipios es una función positiva y lineal de su ingreso, es decir que cada peso adicional que reciba un gobierno local tendrá la misma utilidad para su gestión sin importar la dimensión de los ingresos del municipio.
3. Los ingresos municipales dependen de su recaudo interno y no hay aumentos de los ingresos derivados de la asociación de municipios en un área metropolitana.

4. El mecanismo por el cual los municipios generan sus políticas públicas es el mismo, esto es, que con una inversión determinada tienen exactamente la misma capacidad de proveer bienes y servicios a su comunidad ${ }^{7}$.

5. Existen problemas reales que afectan de manera negativa la propensión de los votantes a elegir al gobierno actual y cuya escala no es municipal sino supramunicipal, asociados al desaprovechamiento de economías de escala-que tiene como consecuencia la prestación ineficiente de servicios públicos-y la generación de externalidades derivadas del uso del suelo, tales como la contaminación ambiental. Estos problemas pueden ser solucionados mediante la cooperación.

6. Sin embargo, esta afectación tiene un efecto marginal mínimo sobre las preferencias de la ciudadanía y solo es significativa por su efecto de acumulación en el largo plazo, es decir que no existen cambios sustanciales en dicha propensión dentro del mismo periodo de gobierno debido a dichas externalidades ${ }^{8}$.

\footnotetext{
6 Los modelos de teoría de juegos que explican la gobernanza metropolitana generalmente prescinden de consideraciones sobre el grado en el cual las acciones de gobierno están determinadas por los votantes, definiendo como actores a los gobiernos municipales (ver al respecto Steinacker, 2004).

7 Este supuesto no pretende corresponderse perfectamente con la realidad, sino evadir consideraciones puntuales que complejizarían el modelo explicativo más allá de las pretensiones del presente documento.

8 El supuesto de información completa del modelo inicial de Downs llega, en este trabajo, hasta la decisión de votar por parte de los electores. Las asimetrías de información relacionadas con la presencia de externalidades y el
} 
7. En el esquema de cooperación metropolitano los recursos gestionados por la entidad central son invertidos con criterios similares a los cuales utiliza cada gobierno municipal para gestionar sus propios recursos, siempre que el alcalde del municipio participe en la toma de decisiones de la entidad central. Así, la decisión acerca de la inversión en un esquema en el que los municipios pueden influir no es cómo invertir los recursos, sino cuánto invertir.

8. Los municipios pueden leer perfectamente las preferencias de sus votantes (existe información completa) en relación con su decisión de voto, y gastan todos los recursos en la vigencia en la que los reciben. Así, la decisión a la que se enfrentan los municipios no es la de cuánto invertir, sino la de cómo invertir de acuerdo con su lectura de las preferencias de los ciudadanos.

De esta manera, los supuestos descritos, tanto desde Downs como a partir de la ampliación para esta investigación particular indican una situación en la cual los gobiernos municipales son idénticos en todo menos en las características de sus ciudadanos y en las dotaciones presupuestales de las que disponen al inicio de cada vigencia.

Es evidente que, en las condiciones enunciadas, el mecanismo de maximización de la utilidad de los municipios los llevaría a no cooperar. Si no existen ingresos adicionales a los regulares, y un municipio obtiene ganancias derivadas de la cooperación, al menos uno de los demás municipios se encontraría en desventaja y preferiría no cooperar, con lo que otro municipio debería asumir el costo que deja el anterior, y así sucesivamente hasta que cada uno actúe autónomamente sin cooperación. Así, aunque existen problemas para la gestión municipal derivados de la metropolización (como se mencionó en el supuesto 5) que afectan negativamente la vida de los votantes, esos problemas no amenazan la permanencia en el poder del gobierno municipal y, por tanto, son menores a los costos que enfrentaría el municipio si cooperara.

La ciencia política ha analizado desde comienzos del siglo xx diversos esquemas institucionales para la gobernanza metropolitana, cada uno con supuestos ligeramente distintos que dieron lugar a diseńos institucionales diversos. Antes de analizar el caso colombiano, es pertinente revisar estas posturas institucionales partiendo de nuestro modelo básico de elección racional.

Desde la ciencia política existen cuatro escuelas que abordan la gobernanza metropolitana: la del gobierno metropolitano o viejo regionalismo, la de la elección pública o policentrismo, el denominado nuevo regionalismo, y la escuela del reajuste y la reterritorialización

desaprovechamiento de economías de escala corresponden a decisiones de los ciudadanos con respecto a sus patrones de producción y consumo, de las cuales se derivan externalidades, no ya a su decisión electoral. La importancia de estas asimetrías de información en el problema del gobierno metropolitano ha sido ampliamente mencionada en la literatura aplicada (Ostrom, Tiebout y Warren, 1961; Tomàs, 2012). 
(rescaling and reterritorialization) $)^{9}$ (Savitch y Vogel, 2009). Cada una de estas perspectivas teóricas está relacionada con una concepción de la "mejor" solución institucional al problema metropolitano de la no corrección de externalidades, y el desaprovechamiento de economías de escala en la producción de bienes y la provisión de servicios públicos, es decir que, además de describir, tiene aspiraciones prescriptivas (Tomàs, 2012).

La primera solución al problema metropolitano es mencionada por diversos autores como gobierno metropolitano o reformismo por la tendencia a realizar reformas administrativas para la anexión de los múltiples municipios metropolitanos en un único centro de gobierno (Jouve y Lefèvre, 2006; Lefèvre, 2010; Savitch y Vogel, 2009; Tomàs, 2012; Zimmerman, 2012). Surgió en la primera mitad del siglo xx y consiste en "la idea de un único gobierno metropolitano unitario que provee todos los servicios (urbanos) a todas las personas en el área metropolitana" (Zimmerman, 2012, p. 2), esto es, en la fusión de los gobiernos locales dentro del área metropolitana en un solo gobierno que incluya también a la ciudad central. Los beneficios que se relacionaban con esta solución desde la perspectiva de la administración pública eran la reducción de inequidades fiscales entre los municipios y el mejoramiento de la capacidad de planeación estratégica para la región, tanto en términos urbanísticos como de planificación del transporte (Savitch y Vogel, 2009).

En términos de las características planteadas por nuestro modelo de elección racional, la solución propuesta desde el reformismo es, por así decirlo, la solución trivial. Entendiendo que no existen incentivos para que los municipios cooperen por su propia cuenta y solucionen las externalidades que se generan mutuamente, la solución evidente es disolver la división político-administrativa original y centralizar el poder en una sola entidad que resuelva tanto los problemas originalmente intramunicipales como los metropolitanos.

La implementación de soluciones de este tipo al problema de la metropolización en Estados Unidos durante el siglo XIX ${ }^{10}$ trajo consigo dificultades que fueron evaluadas $\mathrm{y}$ reseñadas por académicos en el siglo $\mathrm{xx}$, tal como lo resaltan Savitch y Vogel (2009). La primera se desprende del hecho de que no existe evidencia que permita afirmar que el gobierno metropolitano es más efectivo por incluir economías de escala en la gestión pública, o más eficiente por superar las relaciones de conflicto y competencia entre unidades

9 En esta reseña de las principales posturas con respecto al análisis regional en política urbana se omite la postura denominada reescalamiento y reterritorialización. Dicha omisión es intencional, por considerar que los principales elementos analizables desde el punto de vista de la elección racional para el presente trabajo se encuentran contenidos en el nuevo regionalismo. Para una mayor ilustración sobre la postura del reescalamiento y la reterritorialización como mecanismo de corrección de los problemas derivados de la metropolización, consultar Savitch y Vogel (2009).

10 Si bien diversos autores coinciden en señalar el comienzo del siglo xx como el punto en el cual comenzó la investigación sobre el gobierno de áreas metropolitanas, existen esfuerzos centralizadores en los gobiernos metropolitanos durante el siglo xIx. Savitch y Vogel (2009) mencionan los casos de Nueva Orleans (1805), Filadelfia (1854), San Francisco (1856) y Nueva York (1898). 
administrativas menores. En segundo lugar, estos autores afirman que la fragmentación política permitió una mayor participación de minorías étnicas en Estados Unidos, especialmente de las comunidades negras, y la consolidación de una metrópoli, donde tuvo lugar, limitó dicha participación. En tercer lugar, la provisión de servicios e infraestructura por parte de una metrópoli generalmente se centra en los asentamientos periféricos en desmedro del centro de la ciudad, es decir, pone demasiada atención en la "metrópoli", descuidando el ámbito local (Savitch y Vogel, 2009).

La principal crítica a esta forma de enfrentar la metropolización fue la presentada por los partidarios de la teoría de la elección pública. Desde su punto de vista, los gobiernos fragmentados garantizan un mayor nivel de eficiencia y democracia en la prestación de los servicios públicos y la provisión de bienes públicos que la centralización (Savitch y Vogel, 2009; Tomàs, 2012). Uno de los artículos seminales sobre esta postura es el de Ostrom, Tiebout y Warren (1961), en el que aportan la justificación teórica para su posición. Dicho artículo justifica, a partir de la elección racional, la preferencia por gobiernos locales en lugar de un gobierno centralizador en la medida en que: 1) la competencia entre los distintos municipios por el recaudo de impuestos generará mejoras en la calidad de vida de los habitantes, y 2) los acuerdos entre unidades políticas pequeñas en los que cada una de ellas tiene la posibilidad de aceptar o no son preferibles a las decisiones tomadas desde arriba, porque incentivan en mayor medida el involucramiento de los gobiernos locales.

Esta perspectiva involucra un supuesto adicional a nuestro conjunto: el de que las dotaciones de los municipios al inicio de cada periodo dependen de su capacidad de recaudo, y que los municipios con una mejor oferta de bienes y servicios públicos podrán tener un mayor recaudo que los demás, entendiendo que más ciudadanos estarán dispuestos a pagar más por usar los bienes y servicios provistos por estos municipios (Savitch y Vogel, 2009). Así, el partido político de gobierno debe maximizar la utilidad o ganancia de sus ciudadanos para incentivarlos a votar, pero también puede recurrir a mecanismos que mejoren su ingreso disponible y le permitan invertir más para favorecer en mayor medida el aumento de votos favorables a su partido.

Adicionalmente, este modelo incluye el supuesto de que los ciudadanos pueden movilizarse libremente entre municipios según sus preferencias en cuanto a los bienes y servicios que reciben (Savitch y Vogel, 2009). En la medida en que la salida de ciudadanos representa la pérdida de ingresos, si se piensa la postura de la elección pública en los términos de nuestro modelo original, esta salida limita la posibilidad de recaudar e invertir en relación con una situación en la cual los municipios están más densamente poblados. En consecuencia, también limita la propensión de los ciudadanos a elegir el partido de Gobierno con relación al estadio anterior.

Para los teóricos de la elección pública, la corrección de las externalidades es más eficiente si se realizan acuerdos entre los municipios que si se centraliza el gobierno en una sola entidad (ver, por ejemplo, Ostrom et al., 1961). Este argumento se basa en el hecho de que los municipios directamente implicados pueden tener incentivos para corregir o aprovechar las externalidades, tanto negativas como positivas 
que generan o reciben, con los otros municipios que generan o reciben esas externalidades, pero no con los demás.

Adicionalmente, la preferencia por las negociaciones por sobre la centralización puede interpretarse como la consideración de que los supuestos 1 y 6 no se cumplen cabalmente, es decir que, o bien los ciudadanos pueden distinguir qué parte de los bienes que les son provistos corresponde a la autoridad metropolitana y cuál a la autoridad municipal, o bien el Gobierno centralizado no optimiza sus recursos de la forma en la que lo haría el gobierno local. En cualquiera de los dos casos, la situación más eficiente para resolver las externalidades es la que incluye directamente a los municipios, y no a un órgano externo creado a partir de estos. Así, sobre la centralización multilateral en oposición a los acuerdos bilaterales, Ostrom et al. (1961) afirman que:

Irónica, pero lógicamente, este esfuerzo por evitar el recurso a los conflictos, y la consecuente centralización de la toma de decisiones, tiende también a reducir la autonomía local o el grado de independencia ejercida por los gobiernos locales. La presión por un acuerdo en una aproximación común [bilateral o multilateral, no centralizada] a algún problema metropolitano limita las decisiones posibles para cualquier gobierno local. Sin embargo, este rango de decisiones puede incluso ser mayor que el que resultaría del establecimiento de una autoridad central. La negociación entre agencias independientes permite el uso de veto ante una posición inaceptable (Ostrom et al., 1961, p. 842).
La perspectiva de la elección pública ha tenido distintas críticas. Savitch y Vogel (2009) señalan las siguientes. En primer lugar, citando a Downs $(1994)^{11}$, los autores afirman que las unidades políticas periféricas tienen incentivos para restringir, mediante medidas de gestión del suelo, el acceso a sus jurisdicciones de cierto tipo de familias, agravando el problema de desigualdad entre localidades. Segundo, el supuesto de la libre movilidad de personas no se cumple en los hogares de menores ingresos, en donde el costo de movilizarse es muy alto. En tercer lugar, las metrópolis fragmentadas pocas veces tienen los niveles óptimos de cooperación, es decir que "la cooperación metropolitana, cuando ocurre, tiende a ser débil y a estar limitada a asuntos no controversiales" (Savitch y Vogel, 2009, p. 112).

La crítica de Downs al modelo de la elección pública para el gobierno regional, siguiendo el análisis de nuestro modelo básico con información completa, amplía las capacidades de los municipios, renunciando a los supuestos c) y 2). En su criterio, las acciones de gobierno no dependen solo de lo que esperan de sus votantes y contrincantes, sino también de las condiciones de los municipios vecinos para impulsar políticas que promuevan o desincentiven el movimiento de personas a ciertas zonas, por lo que los gobernantes no dedican todos sus recursos a satisfacer a los ciudadanos en cuanto a bienes y servicios públicos, sino que pueden decidir renunciar a ganar recursos (o, lo que es lo mismo, a invertir recursos) al

11 El texto no fue revisado directamente. Su referencia bibliográfica es: Anthony Downs, (1994). New visions for Metropolitan America. Washington DC: Brookings. 
impedir la afluencia masiva de personas o el florecimiento de ciertas actividades económicas dentro de sus fronteras.

La tercera aproximación, que responde al "viejo regionalismo" de los reformistas y a las debilidades evidenciadas en la escuela de la elección pública, es el nuevo regionalismo, que se enfoca en el concepto de ciudad-región. Como afirma Tomàs (2012):

En contraste con los enfoques previos centristas y policentristas, los regionalistas afirman que existen intereses comunes entre las ciudades centrales y los suburbios, tales como el transporte público (Orfield, 1997). Para esos autores, las áreas metropolitanas están hechas de municipalidades independientes y otros actores públicos y privados que deben cooperar para enfrentar problemas comunes (Wallis, 1994). En lugar de crear grandes gobiernos, arreglos flexibles que incluyen una pluralidad de actores son la mejor manera de promover competitividad económica y enfrentar las desigualdades sociales y la expansión urbana (p. 556).
Como se observa, el desarrollo secuencial de las posturas frente al Gobierno metropolitano representa, necesariamente, una postura evolutiva en la cual las nuevas propuestas son siempre respuestas, posibles soluciones, a los problemas de las anteriores, consideradas imperfectas. En el caso del nuevo regionalismo, establece la solución como una agenda política intermedia entre la independencia promovida por la elección pública y la integralidad propuesta por el reformismo (tabla 1). La agenda del nuevo regionalismo

...busca reducir las disparidades sociales, económicas y fiscales entre las ciudades centrales y sus suburbios. Así, los nuevos regionalistas favorecen la participación mutua en los impuestos de los gobiernos locales para asegurar una base fiscal adecuada para las localidades, vivienda adecuada en los suburbios para reducir la segregación y enfrentar el desbalance espacial entre los lugares de trabajo y residencia, y políticas inteligentes de crecimiento para detener la inversión del gobierno federal,

TABLA 1. CARACTERÍSTICAS DE LAS PRINCIPALES APROXIMACIONES A LA GOBERNANZA METROPOLITANA

\begin{tabular}{|c|c|c|c|}
\hline & Concepción de los arreglos institucionales & Objetivos normativos & Escala favorecida \\
\hline $\begin{array}{c}\text { Reformismo } \\
(1900-1920 / 1950-1960)\end{array}$ & $\begin{array}{l}\text { Gobierno metropolitano con autonomía } \\
\text { legal y financiera, cubriendo el territorio } \\
\text { funcional y con miembros elegidos directa- } \\
\text { mente (un nivel o dos) }\end{array}$ & $\begin{array}{l}\text { Igualdad } \\
\text { Eficiencia } \\
\text { Democracia }\end{array}$ & Metropolitana \\
\hline $\begin{array}{l}\text { Elección pública } \\
\text { (1960-1980) }\end{array}$ & $\begin{array}{l}\text { Autonomía local y fragmentación institucio- } \\
\text { nal. Cooperación voluntaria, de ser necesaria. }\end{array}$ & $\begin{array}{l}\text { Eficiencia } \\
\text { Democracia } \\
\text { Competitividad } \\
\text { económica }\end{array}$ & Local \\
\hline $\begin{array}{l}\text { Nuevo regionalismo } \\
(1990-. . .)\end{array}$ & $\begin{array}{l}\text { Relaciones flexibles y horizontales entre } \\
\text { actores públicos y privados regionales (del } \\
\text { gobierno a la gobernanza) }\end{array}$ & $\begin{array}{l}\text { Igualdad } \\
\text { Democracia } \\
\text { Competitividad } \\
\text { económica }\end{array}$ & Metropolitana \\
\hline
\end{tabular}

Fuente:Tomàs (2012) (traducción propia). 
estatal y local en medidas que fomenten la expansión, y canalizar el crecimiento a la ciudad central (Savitch y Vogel, 2009, p. 113).

En términos del modelo planteado inicialmente, el nuevo regionalismo agrega a la gobernanza regional actores privados, es decir, agrega el supuesto de que la dinámica de gobierno del entorno metropolitano no depende únicamente de las decisiones de los gobiernos municipales, sino también de actores privados, representados en empresarios y grupos de interés, que tienen ofertas y demandas políticas que también superan el ámbito municipal. En segundo lugar, el nuevo regionalismo agrega el supuesto de que, debido a todas las posibilidades mencionadas en los modelos anteriores (por ejemplo, la libre movilidad de personas y la capacidad de que los municipios establezcan políticas restrictivas), es posible construir un consenso regional entre los gobiernos, de tal forma que las externalidades negativas derivadas de la metropolización sean tenidas en cuenta por los gobiernos municipales, tanto a la hora de ejecutar políticas como de regular el comportamiento de sus ciudadanos.

\section{LAS ÁREAS METROPOLITANAS EN COLOMBIA Y LOS INCENTIVOS PARA LA COOPERACIÓN DE LOS MUNICIPIOS}

Antes de la Ley 1625

Como entidades jurídicas, las áreas metropolitanas (AM) en Colombia comienzan con la reforma constitucional de $1968^{12}$, que permite su creación, pero no reglamenta su funcionamiento. Solo hasta la promulgación del Decreto-Ley 3104 de 1979 se concretarán las condiciones para la creación y el funcionamiento de las áreas metropolitanas. Posteriormente, la Ley 128 de 1994 genera disposiciones específicas concernientes a las capacidades, la organización administrativa y los ingresos de las AM en el país. Sin el ánimo de presentar exhaustivamente las características de cada marco normativo, la tabla 2 resume los principales elementos del Decreto-Ley 3104 de 1979 y la Ley 128 de 1994 en cuanto a la organización administrativa, funciones, financiación y requisitos para la constitución de las AM (tabla 2).

La reforma constitucional que dio lugar a la elección popular de alcaldes en Colombia tuvo lugar en 1986, por lo que el DecretoLey 3104 de 1979 no se ajusta a los supuestos de nuestro modelo básico con información completa. Sin embargo, la Ley 128 sí se ajusta en gran medida, y la comparación entre uno y otro marco normativo permite identificar elementos introducidos por la ley, en cuanto a incentivos, para promover la cooperación entre los municipios.

Los criterios para la constitución de AM entre 1979 y 1994 incluían el concepto del gobierno central, a través del DNP, y del departamental, a través de la asamblea departamental, por lo que el nivel municipal tenía muy poca incidencia real sobre la decisión de constituir un área metropolitana, en contra de uno de los

\footnotetext{
12 "En cuanto al orden municipal, la reforma de 1968 fue fecunda, en el sentido de aportar nuevas formas de organización municipal, como las de las áreas metropolitanas, las asociaciones de municipios y las juntas administradoras locales" (Vidal, 1981, p. 24).
} 
TABLA 2. ANTECEDENTES DE LA LEY 1625 DE 2013. ORGANIZACIÓN, FUNCIONES, FINANCIACIÓN Y CONSTITUCIÓN

\begin{tabular}{|c|c|c|}
\hline & Decreto-Ley 3104 de 1979 & Ley 128 de 1994 \\
\hline $\begin{array}{l}\text { Organización } \\
\text { administrativa }\end{array}$ & $\begin{array}{l}\text { Alcalde metropolitano: el alcalde del municipio } \\
\text { núcleo o metrópolis preside la junta metro- } \\
\text { politana y puede objetar las decisiones de la } \\
\text { junta metropolitana. Adicionalmente, tiene } \\
\text { competencias para celebrar contratos en nom- } \\
\text { bre del AM. } \\
\text { Junta metropolitana: el alcalde metropolitano } \\
\text { como presidente, un representante del conce- } \\
\text { jo del municipio núcleo, un representante del } \\
\text { concejo municipal de uno de los municipios } \\
\text { periféricos, un alcalde de los municipios pe- } \\
\text { riféricos y otro adicional si el Am tiene más de } \\
\text { cinco municipios. }\end{array}$ & $\begin{array}{l}\text { Alcalde metropolitano: el alcalde del municipio } \\
\text { núcleo o metrópolis, preside la junta metropo- } \\
\text { litana y puede objetar las decisiones de la junta } \\
\text { metropolitana. } \\
\text { Junta metropolitana: un representante del concejo } \\
\text { del municipio núcleo, un representante de los con- } \\
\text { cejos periféricos, los alcaldes de todos los munici- } \\
\text { pios y el gobernador o su secretario de planeación. } \\
\text { Gerente del AM: nombrado por el alcalde metro- } \\
\text { politano. } \\
\text { Consejo metropolitano de planificación: conforma- } \\
\text { do por el gerente, los directores de planeación } \\
\text { de los municipios y el director de planeación del } \\
\text { departamento. }\end{array}$ \\
\hline $\begin{array}{l}\text { Principales } \\
\text { funciones }\end{array}$ & $\begin{array}{l}\text { De planificación, de prestación de servicios pú- } \\
\text { blicos, relativas a la contribución de valorización } \\
\text { y de coordinación administrativa. }\end{array}$ & $\begin{array}{l}\text { Programar y coordinar el desarrollo, racionalizar la } \\
\text { prestación de servicios públicos y ejecutar obras de } \\
\text { interés metropolitano. } \\
\text { Declarar hechos metropolitanos y servir de autori- } \\
\text { dad en lo concerniente a dichos hechos. } \\
\text { Promulgar el Plan Integral de Desarrollo Metro- } \\
\text { politano. }\end{array}$ \\
\hline Financiación & $\begin{array}{l}\text { No especificados: transferencias de entidades } \\
\text { territoriales y recaudos por valorización y pres- } \\
\text { tación de servicios, principalmente. }\end{array}$ & $\begin{array}{l}\text { Los mismos establecidos en el régimen anterior, } \\
\text { más una sobretasa del dos por mil sobre el avalúo } \\
\text { catastral de las propiedades situadas dentro de su } \\
\text { jurisdicción, con destinación específica ambiental. }\end{array}$ \\
\hline Constitución & $\begin{array}{l}\text { Se autorizó la creación de las AM centradas en } \\
\text { Medellín, Cali, Barranquilla, Bucaramanga y } \\
\text { Pereira. De ahí en adelante, la conformación } \\
\text { debe darse con el concepto positivo del De- } \\
\text { partamento Nacional de Planeación (DNP) y por } \\
\text { ordenanza departamental. }\end{array}$ & $\begin{array}{l}\text { Por consulta popular convocada por iniciativa ciu- } \\
\text { dadana o de los alcaldes. }\end{array}$ \\
\hline
\end{tabular}

Fuente: elaboración propia a partir del Decreto-Ley 3104 de 1979 y la Ley 128 de 1994.

Definiciones:

Municipio núcleo: el municipio de mayor tamaño o metrópolis.

Municipios periféricos: los demás municipios que conforman el AM.

Alcalde metropolitano: el alcalde del municipio núcleo, con la mayor concentración de competencias en el AM. 
principales supuestos de nuestro modelo: que la conformación de un AM depende de la cooperación de municipios. Adicionalmente, su esquema de gobierno no incluía la participación de todos los municipios, sino únicamente del central y de dos adicionales: uno mediante un representante de su concejo y otro mediante su alcalde. Esto significa que, en la medida en que no participa el gobierno de todos los municipios, el supuesto 7 de nuestro modelo no se cumple necesariamente.

Con la Ley 128 de 1994, las condiciones se acercan más a las de nuestro modelo inicial. A pesar de que el municipio núcleo tiene concentradas más competencias en la figura del alcalde metropolitano, la pertenencia de todos los municipios a la junta metropolitana permite que el esquema real se aproxime al modelo, mediante la participación de los municipios periféricos en la toma de decisiones. Los mecanismos para la constitución de las AM y los recursos que reciben son los dos elementos en los que coinciden los requisitos para la cooperación del modelo inicial con información completa y el diseño institucional propuesto en la ley.

En primer lugar, el requisito de refrendación en consulta popular de la decisión de conformar un área metropolitana está de acuerdo con el supuesto según el cual los gobernantes municipales toman todas sus decisiones en función de la maximización de votos. En segunda instancia, la adición de ingresos de recaudo municipal sobre el catastro con destinación específicamente ambiental constituye la fuente de los ingresos adicionales que se mencionaron como necesarios para la cooperación metropolitana en nuestro modelo.
Así, la elección popular de alcaldes trajo modificaciones a la normativa, que se ajustan al modelo básico de elección racional planteado: la consideración de que los gobernantes maximizan los votos favorables, coherente con la refrendación popular de la conformación de un AM, y la consideración de la necesidad de mayores recursos para la gestión metropolitana de los que recaudaría autónomamente el municipio. La normativa posterior, que constituye el objeto central de este documento, modifica ligeramente estas prescripciones y aumenta los requisitos para la cooperación, como se evidenciará a continuación.

Incentivos para la cooperación metropolitana después de la Ley 1625 de 2013 T2

Para la constitución de un área metropolitana, la Ley 1625 de 2013 establece que es necesaria la aprobación de los alcaldes de los municipios interesados, la tercera parte de los concejales, el cinco por ciento de los ciudadanos del censo electoral en los municipios, y el gobernador o los gobernadores de los departamentos a los que pertenezcan los municipios interesados. Adicionalmente, debe tenerse claro desde el principio cuál será el municipio núcleo, el conjunto de municipios integrantes y las razones que justifican su constitución (Ley 1625, 2013, art. 8). Así, la constitución de un AM no es una decisión autónoma de los alcaldes municipales y, además, es costosa desde el punto de vista de las administraciones municipales, puesto que los municipios deben destinar recursos para tramitar la conformación del AM, que de otro modo destinarían a inversión siguiendo el modelo inicial.

Las competencias de las AM según la Ley 1625 son, salvo una, similares a las funciones 
establecidas en la Ley 128 de 1994. La primera de ellas es la programación y coordinación del desarrollo "armónico, coordinado y sustentable" de los municipios que la integran. La segunda, la racionalización ${ }^{13}$ (y eventual prestación) de los servicios públicos dentro del mismo territorio. La tercera corresponde a la ejecución de obras de infraestructura vial y el desarrollo de proyectos de interés social (Ley 128, 1994, art. 4; Ley 1625, 2013, art. 6). La competencia adicional, agregada por la Ley 1625 de 2013, consiste en la promulgación de las directrices específicas para el ordenamiento territorial de los municipios que la integran, de tal forma que se armonicen sus Planes de Ordenamiento Territorial (Ley 1625, 2013, art. 6). Adicionalmente, la Ley 1625 confiere a las AM las funciones de autoridad de medio ambiente y de transporte público, y coordinar las políticas de vivienda social, entre otras funciones (Ley 1625, 2013, art. 7). En general, puede decirse que, por sus competencias, las AM se definen como planeadoras del desarrollo, el ordenamiento territorial y la movilidad, así como de programas metropolitanos de vivienda; coordinadoras de la implementación de políticas nacionales de vivienda de interés social (vis) y reguladoras en temas de medio ambiente, servicios públicos y transporte público.

Como instrumentos para la planeación y el control de los fenómenos que sobrepasan el ámbito municipal la ley establece la formulación del Plan Integral de Desarrollo Metropolitano y el Plan Estratégico Metropolitano de Orde- namiento Territorial, así como la declaratoria de Hechos Metropolitanos. A continuación se resumen las características, consignadas en la ley, de cada uno de estos instrumentos.

\section{Hechos metropolitanos}

Según la Ley 1625, los hechos metropolitanos son "aquellos fenómenos económicos, sociales, tecnológicos, físicos, culturales, territoriales, políticos o administrativos, que afecten o impacten simultáneamente a dos o más de los municipios que conforman el área metropolitana" (Ley 1625, 2013, art.10) ${ }^{14}$.

Para su determinación, los hechos metropolitanos deben satisfacer los criterios de alcance territorial, eficiencia económica, capacidad financiera, capacidad técnica, organización político-administrativa e impacto social. La satisfacción de estos criterios se hace efectiva cuando la atención del hecho metropolitano demanda más de lo que puede ofrecerse en el nivel municipal, pero igual o menos de lo que se puede ofrecer desde el metropolitano. Es decir, un hecho metropolitano es un problema que cumple con las condiciones planteadas en el supuesto 5 del modelo inicial con información completa.

La planeación de los asuntos correspondientes a los hechos metropolitanos, en lo relativo al ordenamiento territorial, debe estar consignada en el Plan Integral de Desarrollo Metropolitano y las Directrices Metropolitanas de Ordenamiento Territorial.

\footnotetext{
13 Entendida como el ordenamiento eficiente de la prestación de los servicios públicos.

14 Los hechos metropolitanos no son una novedad de la Ley 1625 de 2013. También hicieron parte de la Ley 128, si bien entonces no se los definió puntualmente.
} 


\section{Planes Integrales de Desarrollo Metropolitano}

Los instrumentos de planeación que articulan las funciones de las áreas metropolitanas con la atención a los hechos metropolitanos son los planes integrales de desarrollo metropolitano (PIDM). Estos planes constituyen un marco de acción de largo plazo para que las políticas públicas ejecutadas, tanto por el área metropolitana como por cada municipio, converjan en un mismo objetivo, estén coordinadas y favorezcan el desarrollo de todos los municipios dentro de la jurisdicción. Son una norma de superior jerarquía, es decir que determinan los planes de ordenamiento territorial y los planes de desarrollo municipal en lo referente a los hechos metropolitanos. El PIDM es un instrumento que aparece dentro de la normativa desde 1979. De acuerdo con el Decreto-Ley 3104, la entidad encargada de formularlo era la dirección de Planeación del municipio central, mientras que según la Ley 128 y la 1625, la formulación del PIDM es una competencia del AM como entidad (Decreto 3104, 1979; Ley 128, 1994; Ley 1625, 2013).

\section{Plan Estratégico Metropolitano de Ordenamiento Territorial}

El Plan Estratégico Metropolitano de Ordenamiento Territorial (Ремот), por su parte, debe precisar el modelo de ocupación de la región metropolitana, centrándose en algunos puntos específicos, e incluyendo un programa de acción determinado tanto para la intervención del AM como para la de los municipios. Como mínimo, el PEMot debe definir la estrategia para la gestión integral del agua, el sistema metropolitano de vías y transporte público, el sistema de equipamientos metropolitanos, la estrategia para la vivienda social y prioritaria, el ordenamiento del suelo rural y suburbano, los mecanismos de reparto de cargas y beneficios, y el programa de ejecución (Ley 1625, 2013, art. 22).

El ремот es una novedad de la Ley 1625 y tiene características similares en lo relativo al ordenamiento territorial y al Plan Integral de Desarrollo Metropolitano. Sin embargo, este plan especifica la planeación en la movilidad regional, el transporte metropolitano, la estrategia de gestión de agua y la vivienda social y prioritaria como aspectos particulares. Además, la ley define la obligatoriedad de la conformación de un expediente metropolitano como mecanismo de seguimiento al cumplimiento del modelo de ocupación plasmado en el PEMOT.

A partir de la Constitución de 1991 surgieron diferentes piezas normativas para el fortalecimiento del modelo de descentralización del país, que en algunos casos se relacionan con las competencias de las AM. En particular, la Ley 388 de 1997 y la Ley 1454 de 2011, en términos de planeación; la Ley 99 de 1993, el Código Nacional de Tránsito (Ley 769 de 2002) y el Decreto 170 de 2001 en cuanto a competencias en temas ambientales y de transporte, respectivamente, inciden en la delimitación de las competencias de las áreas metropolitanas.

\section{Ley 388 de 1997}

En la Ley 388 de 1997 se consignan detalladamente los lineamientos para los planes de ordenamiento territorial (РОт) en el nivel 
municipal, y las herramientas legales y técnicas necesarias para la formulación y ejecución de esos planes. Esta ley concibe las áreas metropolitanas como un ente de planeación de nivel superior a los municipios, pero inferior al nivel departamental y nacional, y antepone las directrices de las áreas metropolitanas sobre las municipales, haciendo obligatoria su consideración para la formulación de los POT municipales (Ley 388, 1997).

\section{Ley 99 de 1993}

Según la Ley 99 de 1993, las competencias de las áreas metropolitanas en materia ambiental, cuando los municipios en su jurisdicción suman más de un millón de habitantes, son idénticas a las de las corporaciones autónomas regionales, es decir, las AM son encargadas de la expedición de licencias ambientales y permisos, y del control de los vertimientos y las emisiones contaminantes, la disposición de desechos sólidos y de residuos peligrosos, así como de dictar las medidas de mitigación del daño ambiental y ejecutar procesos de saneamiento (Ley 99, 1993). De forma similar a como ocurre con las Corporaciones Autónomas Regionales, los recursos derivados de los aportes obligatorios de los municipios al AM en materia ambiental (es decir, el 2 por mil sobre el avalúo catastral), son de destinación específica ambiental. Adicionalmente, la Ley 99 dictamina que los municipios con más de un millón de habitantes que no estén dentro de un AM se constituyen como autoridad ambiental en el área urbana bajo su jurisdicción.

\section{Decreto 170 de 2001}

Este decreto del Ministerio de Transporte es el que reglamenta el servicio público de transporte terrestre automotor colectivo en el ámbito local. Cuando existe un área metropolitana en términos funcionales -es decir, un área conurbada, bien sea que se haya declarado un AM o no-, este decreto le confiere a los municipios la competencia para ejercer en común la función de autoridad de transporte público colectivo o crear una autoridad única de transporte metropolitano (Ministerio de Transporte, 2001). Así, esta pieza normativa es la primera en posibilitar el ejercicio de la autoridad metropolitana por parte de las AM, antes de la Ley 1625.

\section{Organización administrativa de las AM según la Ley 1625}

El principal órgano administrativo de las áreas metropolitanas es la Junta Metropolitana. Al interior de la misma, los alcaldes de los municipios miembros -incluido el municipio núcleo-, un representante del concejo del municipio núcleo y uno de los demás concejos tienen voz y voto, mientras que los demás integrantes -a saber, un delegado permanente del Gobierno nacional y los presidentes de los consejos asesores metropolitanos (generalmente el director del área metropolitana) - tienen voz pero no voto.

El municipio núcleo tiene un papel preponderante en todas las instancias de las AM. Además de que su alcalde es el presidente de 
la junta metropolitana, es el único municipio cuyo concejo tiene un representante permanente en dicho órgano. Adicionalmente, el presidente de la junta es el único miembro con el poder de sancionar los acuerdos metropolitanos, expedir decretos metropolitanos y remover de su cargo al director del AM.

Así, el municipio núcleo tiene tres representantes en la Junta Metropolitana: el alcalde, que cumple la función de presidente y tiene, en consecuencia, unas responsabilidades y facultades específicas; un miembro del concejo municipal, y, sin voto pero con voz, el director del AM que, si bien no es un funcionario del municipio núcleo, sí es nombrado a partir de la terna presentada por el alcalde. Teniendo en cuenta que, según la misma ley, las decisiones tomadas en la junta metropolitana se toman por mayoría simple, la influencia del municipio núcleo en esas decisiones es mayor que la de los demás municipios integrantes. Adicionalmente, el plan integral de desarrollo metropolitano, el plan de inversiones y el presupuesto anual de rentas y gastos del área metropolitana, así como la elección del director del AM deberán tener el voto afirmativo del presidente de la lunta, lo que aumenta la influencia del alcalde del municipio núcleo en las políticas metropolitanas (Ley 1625, 2013, art. 19).

\section{Financiación}

La Ley 1625 no modifica lo concerniente a patrimonio y rentas con respecto a la Ley 128 de 1994. En su artículo 28, la ley enumera las fuentes de ingresos de las AM, entre las cuales algunas dependen de las decisiones de distintas entidades territoriales y otras están dirigidas a estas áreas de forma fija a partir de la ley. Mientras que algunas de sus fuentes de ingreso le corresponden al AM independientemente del criterio de las autoridades territoriales y la nación, otras dependen de este criterio.

Los ingresos de las AM que no dependen de las entidades territoriales son, fundamentalmente, provenientes de la sobretasa del dos por mil sobre el avalúo catastral de todos los inmuebles ubicados en la jurisdicción de dicha área. Esta sobretasa se sustenta en el artículo 317 de la Constitución, como destinación de recursos a "entidades encargadas del manejo y conservación del ambiente" (Constitución Política de Colombia, art. 317).

\section{DISCUSIÓN}

Como se evidenció, en lo que respecta a la metropolización, la normativa colombiana se acercó, inicialmente, más a una posición centralista que a una policéntrica, de acuerdo con las teorías mencionadas en la primera parte del artículo. Esta posición, si bien no estaba completamente centralizada, privilegiaba las decisiones del municipio núcleo o metrópoli, específicamente en lo relacionado con la planeación del desarrollo y la racionalización de los servicios públicos.

Posteriormente, la Ley 128 de 1994 les dio participación a los demás municipios y amplió las capacidades de estas entidades, fomentando en mayor medida un escenario policéntrico en la junta metropolitana, si se entiende como un espacio para la discusión y la toma de decisiones. Sin embargo, el PIDM 
como instrumento principal para establecer lineamientos de desarrollo regional centraliza las decisiones de mediano y largo plazo, y se opone a las características de un sistema policéntrico.

En cuanto a la Ley 1625, si bien entrega más funciones y competencias a las $\mathrm{AM}$, no es posible determinar a partir de la revisión normativa si permite, por sí misma, la consolidación de un esquema de gobernanza metropolitana bajo el nuevo regionalismo, que idealmente tome los mejores elementos del modelo centralista y del policéntrico. Partiendo del modelo básico con información completa planteado previamente, la cooperación metropolitana en Colombia tiene algunas características que la limitan desde el punto de vista normativo, como las siguientes:

1. El hecho de que el municipio núcleo tenga mayor poder en las decisiones de la junta metropolitana hace menos probable que dichas decisiones sean las que maximizan la utilidad de los municipios periféricos, de menor tamaño.

2. Los altos costos para la conformación de un AM en términos administrativos, y la necesidad de que la iniciativa surja del ámbito municipal -bien sea de las alcaldías, de los ciudadanos o de los concejos-, hacen necesario un beneficio más que proporcional para los municipios (tanto para los gobernantes como para los ciudadanos), de hacer parte de un AM que de actuar de forma autónoma, puesto que si dicho beneficio fuera proporcional, los costos en los que el municipio debe incurrir impedirían la cooperación.
3. El ingreso adicional generado por la sobretasa del 2 por mil sobre el avalúo catastral del municipio tiene una destinación específica ambiental, por lo que se puede suponer que rinde un beneficio menos que proporcional a los municipios de más de un millón de habitantes (municipios núcleo) que si ellos mismos fueran las autoridades municipales ambientales, en cuyo caso podrían gestionar los recursos de forma autónoma.

4. Según la Ley 99 de 1993, pertenecer a una CAR obliga a los municipios pequeños (de menos de un millón de habitantes) a aportar un monto de entre 15 y $25 \%$ del impuesto predial. De forma coherente con lo anterior, pertenecer a un AM solamente será beneficioso bajo el modelo propuesto para el municipio si el 2 por mil sobre el avalúo catastral es inferior al $15 \%$ del recaudo predial, o sea, si su recaudo anual de predial es superior al 1,3\% de su avalúo catastral. Sin embargo, en la medida en que, como se evidenció, existen gastos significativos para conformar un AM, esta cifra debe ser incluso superior para tomar la decisión de conformar un AM.

Siguiendo los parámetros del modelo original existen, como mínimo, tres vías para el fortalecimiento de la cooperación metropolitana en Colombia. En primer lugar, que exista una demanda evidente de los ciudadanos de toda la región por corregir los problemas de ineficiencias y externalidades que se generan entre sus municipios, especialmente de corte ambiental y de prestación de servicios, en cuyo 
caso los municipios encontrarían beneficioso cooperar para gestionar el medio ambiente y planificar la prestación de servicios y el desarrollo urbano. En segundo lugar, que el municipio núcleo, de mayor tamaño y capacidad de recaudo fiscal, perciba una necesidad evidente de los ciudadanos de corregir las externalidades e ineficiencias que se generan en su región y decida aportar voluntariamente un monto más que proporcional que subsidie las pérdidas de los municipios periféricos, mejorando la situación de los alcaldes de dichos municipios e incentivándolos a cooperar. En tercer lugar, que exista una transferencia exógena (por ejemplo, del Gobierno central) para proyectos metropolitanos, tanto ambientales como no ambientales, que les permita, tanto a los municipios periféricos como al núcleo, establecer una relación de cooperación en la medida en que aumente la cantidad potencial de votos.

\section{CONCLUSIÓN}

En el presente documento se utilizó un modelo de elección racional para revisar las principales teorías sobre el gobierno metropolitano (el reformismo, la elección pública y el nuevo regionalismo), la historia de la regulación sobre áreas metropolitanas en Colombia y su estado actual. Se evidenció que los modelos explicativos para el gobierno metropolitano, si bien tienen asiento teórico, buscan prescribir las condiciones necesarias para un mejor gobierno, cuando menos desde el punto de vista de la efectividad en la solución de problemas derivados de la metropolización. En esa medida, cada modelo busca corregir los defectos del anterior.

Se evidenció que la normativa sobre áreas metropolitanas en Colombia respondió a la reforma constitucional de elección popular de autoridades locales a través de cambios en su estructura orgánica y sus competencias, y que en la actualidad dicha normativa tiene componentes centralistas -como la formulación de planes de largo plazo que deben seguir todos sus miembros-, y policéntricos -como la junta metropolitana como espacio de discusión de intervenciones de política-. La existencia de ambos elementos posibilita la consolidación de un modelo de gobierno metropolitano que, a la manera del nuevo regionalismo, combine los aciertos del centralismo y la policentricidad en una forma de gobernanza metropolitana que promueva la cooperación entre los municipios de forma sostenible.

Si se busca un modelo de gobernanza metropolitana que transite hacia el nuevo regionalismo, es decir, uno en el cual se articulen actores públicos y privados con base en las necesidades que surgen dentro de la región, las instituciones que mejor lo incentivan son las que producen las demandas adecuadas desde la ciudadanía a fin de que dichos actores tengan los incentivos correctos para la cooperación. En esa medida, dichas instituciones deben corregir los fallos de información existentes en relación con la generación de externalidades y el desaprovechamiento de economías de escala en la provisión de bienes públicos. Es decir, deben concientizar de forma efectiva a los potenciales votantes de que ambos aspectos 
existen y pueden ser corregidos si se intervienen con una escala metropolitana.

\section{REFERENCIAS}

Barry, B. (1970). Los sociólogos, los economistas y la democracia. Buenos Aires: Amorrortu.

Carrión, G. A. (2009). Los avatares de la institucionalidad metropolitana en Colombia: una breve revisión a la aplicación de la Ley 128 de 1994. Desafios, I(20), 217-252. Recuperado de http:// revistas.urosario.edu.co/index.php/desafios/ article/viewArticle/435

Decreto 3104 (1979). Por el cual se dictan normas para la organización y el funcionamiento de las áreas metropolitanas.

Downs, A. (1992). Teoría económica de la acción política en una democracia. En Diez textos básicos de ciencia politica (pp. 92-111). Bogotá: Planeta.

Ebers, M. y Oerlemans, L. (2013). The variety of governance structures beyond market and hierarchy. Journal of Management, xx. http://doi. org/10.1177/0149206313506938

Jouve, B. y Lefèvre, C. (2006). The organisation of government in European metropolitan areas. Urban Public Economics Review, 91-111.

Lefèvre, C. (2010). The improbable metropolis: decentralization, local democracy and metropolitan areas in the Western world. Análise Social, XLV (197), 623-637.

Ley 128 (1994). Por la cual se expide la Ley Orgánica de las Áreas Metropolitanas.

Ley 1625 (2013). Por la cual se deroga la Ley Orgánica 128 de 1994 y se expide el Régimen para las Áreas Metropolitanas.
Ley 388 (1997). Por la cual se modifica la Ley 9 de 1989, y La ley 2 de 1991 y se dictan otras disposiciones. Ministerio de Transporte (2001). Decreto 170. Por el cual se reglamenta el servicio público de transporte terrestre automotor colectivo metropolitano, distrital y municipal de pasajeros. Bogotá: Ministerio de Transporte.

Ostrom, E. (2015). Comprender la diversidad institucional. México: Fondo de Cultura Económica.

Ostrom, V., Tiebout, C. M. y Warren, R. (1961). The organization of government in metropolitan areas: A theoretical inquiry. The American Political Science Review, 55 (4), 831-842. http://doi. org/10.1126/science.151.3712.868

Savitch, H. y Vogel, R. (2009). Regionalism and urban politics. En Davies, J. S. y Imbroscio, D. L. (eds.). Theories of urban politics (pp. 106-124). London: Sage Publications.

Steinacker, A. (2004). Game-theoretic models of metropolitan cooperation. En Feiock, R. (ed.). Metropolitan governance (pp. 46-67). Washington: Georgetown University Press.

Tomàs, M. (2012). Exploring the metropolitan trap: The case of Montreal. International Journal of Urban and Regional Research, 36 (3), 554-567. http:// doi.org/10.1111/j.1468-2427.2011.01066.x

Vidal Perdomo, J. (1981). ¿Descentralización? ¿Regionalización? ¿Federalismo? Bogotá: Universidad Externado de Colombia.

Williamson, O. (2000). The New institutional economics: Taking stock, looking ahead. Journal of Economic Literature, xxxviII, 595-613. http:// doi.org/10.1257/jel.38.3.595

Zimmerman, U. (2012). Metropolitan governance. Encyclopedia of Public Administration and Public Policy, 11 (3), 1-4. http://doi.org/10.1057/ eps. 2011.42 